was prescribed in pill form, $1 / 4$ to $1 / 2$ grain, according to age, three times a day. Although long retired from practice I recently used this treatment for my housemaid who developed shingles. Relief from the pains quickly followed its administration. Having in mind the close relationship between herpes zoster and varicella, I regret the missed opportunities of treating the latter with cannabis indica when I was in charge of one of the Metropolitan hospitals for infectious diseases. It may allay the irritation of the rash, and I offer the suggestion to anyone who may be interested.

\section{Sir James Mackenzie's Heart}

Dr. A Murdoch (Bexhill-on-Sea) writes: It is a singular coincidence that your editorial on Sir James Mackenzie's heart (July 22, p. 178) should appear in the Journal after the publication of three letters on control of functioning, as the last time I saw my friend, which was just a few months before his death, we had an argument about the way he was "using" himself-that is, controlling his functioning in relation to his anginal pain. I was a fellow sufferer, as he and others had diagnosed that the incapacity from which 1 suffered was anginal; he had ordered me a long rest and to live within my limitations. At that time I had broken away from all orthodox treatment and was receiving re-education lessons in the use of myself by conscious control from F. Matthias Alexander. Sir James Mackenzie was very scornful about this, and to my remark that he was "using" himself very badly in the way he was sitting he replied: "And why can't I sit like this?" The point of this letter is to draw attention to the fact that now when I am entering my 78th year and after sixteen years of " using" myself according to the principles laid down by Alexander, I have kept free from angina, am still in practice, and am able to lead an active life with, of course, some of the limitations due to my age. I would like to add that whereas Alexander's theory and technique were based on empirical ideas at first, they are now known to be based on definite anatomical and physiological principles.

\section{A.R.P. Car Shield}

A steel shield has recently been devised to protect saloon-type motor cars and ambulances from falling shell fragments and debris in time of war. The shield can be mounted or removed by two untrained persons in about two minutes, and it requires no special brackets. It cannot damage the car in any way, and does not appreciably affect its normal performance or driving visibility. The shield covers the entire roof, and projects over the driver's legs and also at the rear to protect passengers in the back seat from fragments falling at a sharp angle. It also extends beyond the roof of the car to either side, though it does not project further than the outer edge of the running-board Supporting blocks ensure a proper distribution of the weight and are covered with rubber to prevent damage to the paintwork. The shield can be fitted to any saloon car, whether the roof be of fabric or of metal. The cost is approximately $£ 4$ for a medium-sized car. Inquiries should be addressed to the Secretary, Ace of Spades Petroleum Company, Ltd. Great West Road, Hounslow, Middlesex.

\section{Delayed Union of Fractures}

Dr. R. LARKIN (London, S.E.) writes: In the Journal of July 29 (p. 219), in an article on delayed union and non-union of fractures, Mr. R. I. Stirling states: "Mineral salt deficiency per se is seldom, if ever, responsible for delayed union or non-union of fractures" I wrote letter to the Journal in 1916 showing that this chemical deficiency operates more frequently than is supposed, and dates from the time when Stimson, surgeon-incommand of the Northern Army during the American Civil War, found that this cause was operative-no doubt in the first place from lack of food in the field-from loss through shock of the mineral salts of the blood, particularly phosphates; the output of phosphates in the urine is not noticeably increased, but a considerable quantity of phosphates is lost by the intestinal secretion. My first case was that of a patient who had been in hospital for nine months; replating, screwing, and adjusting splints had been tried in vain, also thyroid administration, $x$ rays, and freshening the ends of the bones. The patient was a post-office worker under the care of the post office medical officer, who was nonplussed by the case and asked my opinion.' I advised prescribing syr. ferri phos. co.: my advice was followed, with the result that the patient went back to work cured in a few weeks' time with the callus as hard as iron. I remember many such cases ; in one, that of a sergeant-major with Jacksonian epilepsy, instead of trephining I found the exhibition of syr. ferri phos. co. turned the exuberant callus of the gunshot wound of the head into bone and withdrew the pressure from the cerebral cortex. He went back to his regiment recovered. It is quite likely, although Mr. Stirling pronounces the local blood condition normal, that there is some hormonic influence in the treatment that prevents further loss of phosphates and helps the general nervous system to build up the bone. I have treated an intracapsular fracture of the patella like this, and with early movements got the patient walking about in five weeks time.

\section{Children in War Time}

Billeting in Brief is a pamphlet which has just been issued jointly by the National Union of Teachers and the Save the Children Fund. It summarizes information which has appeared in Government and other publications in anticipation of a state of war, and gives in simple form advice and instruction which should be useful to those who might be called upon to look after groups of children. Preparations which should be made for evacuating children are detailed, as are the arrangements necessary for their reception in the areas to which they are taken. Supplementing the general hints there are three appendices giving suggestions for the feeding of children of different ages. These have been contributed by Professor V. H. Mottram. Copies of this pamphlet (price 2d.) may be ordered through any bookseller. or may be obtained direct from the Save the Children Fund 20, Gordon Square, W.C.1.

\section{Chronic Mastitis}

Dr. SIDNEy Pern (Ballarat, Victoria) writes: I am pleased to see that Mr. H. J. B. Atkins (Journal, April 29, p. 866) has pointed out that chronic mastitis "falls into line with the established procedure of Nature in dealing with infectious diseases." I have for a number of years been treating this condition as a specific elective invasion from some chronic focus, the removal of which has resulted in the disappearance of the mastitis. It would be unreasonable to assume that the breast escaped local invasion any more than joints, myocardium, kidneys, or any other tissue, so we have to reconstruct in our minds what sort of pathological picture would be the result of such an invasion going on for months at a time. If by removal of all infected foci consistently satisfactory results be obtained, as has been my own experience, it would be reasonable to assume that the infection was the cause of the condition. Chronic irritation applied to cells which have the power of proliferation sooner or later produces that proliferation, which if carried on indefinitely causes reversion to a more primitive type. The liberation of bacterial toxins produces the necessary irritant. Mr. Atkins, with his large clinic at Guy's, would have ample opportunity to prove or disprove this contention.

\section{Disclaimer}

Dr. Alan Maberly writes: In view of the undesirable and unsolicited Press publicity following the lecture given by me at the Summer School of the British Social Hygiene Council at Oxford, culminating in an article by a Sunday newspaper correspondent based upon an alleged interview with me, I would be grateful if you would publish this disclaimer. All Press correspondents were excluded from my lecture at Oxford, and I have no idea whence the garbled account issued to the Press originated. Subsequently I was informed that an article in a Sunday newspaper had been commissioned, arising from a statement I had been reported to have made. The alleged interview occupied precisely three minutes and was devoted to requesting and obtaining an assurance that my name would not be used in any way in connexion with such an article.

\section{Corrigendum}

There was a misprint in the text of Sir Joseph Barcroft's paper on Food Conservation in Relation to National Food Supply published last week. On page 326, column 1, line 19 from the foot, the phrase "washed potato" should have been "mashed potato." 